\title{
Cardiovascular Risk Assessment and Effects on Behavior in Switzerland The Swiss Heart Foundation HerzCheck ${ }^{\circledR}$ Cardio-Test $^{\circledR}$
}

\author{
Niclas Freund ${ }^{\mathrm{a}}$, Bernhard C. Friedli ${ }^{\mathrm{b}}$, Therese Junker ${ }^{\mathrm{c}}$, Martin Zimmermann ${ }^{\mathrm{c}}$ and \\ Michael J. Zellweger ${ }^{\mathrm{a}, *}$
}

${ }^{a}$ University Hospital Basel, Cardiology Department, Switzerland

${ }^{b}$ Kantonsspital Baden, Cardiology Department, Switzerland

${ }^{c}$ Swiss Heart Foundation, Bern, Switzerland

\begin{abstract}
Background: "CardioTest ${ }^{\circledR}$ is a tool for cardiovascular risk assessment. The aim of this study was to evaluate if this test used in Swiss pharmacies provides risk stratification and if it had impact on individual behaviour.

Methods: Individuals were evaluated (blood pressure, body waist circumference, random blood samples and coronary artery disease risk factors). The cardiovascular risk was calculated (AGLA Risk Score (ARS) a modified PROCAM Score) and participants were informed about their result. One year after the initial testing individuals were followed up by questionnaire with respect to the action they had taken based upon the ARS results. The relation between ARS results and events during follow-up were assessed. Events were defined as cardiovascular events due to chest pain, myocardial infarction or stroke.

Result: A total of 1415 individuals were contacted for follow-up, $746(53 \%)$ with a mean age of $62.7( \pm 12.8)$ years $(60 \%$ were male) returned their questionnaire. The cardiovascular risk throughout the study-population turned out to be low: $73.9 \%$ had a low ARS $<10 \%, 21.7 \%$ an intermediate ARS $10-20 \%$ and $4.4 \%$ had a high ARS $>20 \%$. Significantly more participants with ARS $>20 \%$ consulted their family doctor (46.2\%) than those with ARS $10-20 \%(25.2 \%)$ and ARS $<10 \%$ $(10.4 \%)$, respectively ( $<<0,01$ for both comparisons). Sixty-four individuals $(9 \%)$ suffered a cardiovascular event. The event rates increased as a function of ARS.

Conclusion: The overall cardiovascular risk of individuals participating in a pharmacy based risk assessment program seems to be low. CardioTest ${ }^{\circledR}$ provided risk stratification with respect to future cardio-vascular events. CardioTest ${ }^{\circledR}$ seems to have impact on individual behavior and lifestyle modification. Other settings and locations for screening might be considered to reach higher risk individuals at an earlier stage.
\end{abstract}

Keywords: Coronary artery disease, risk factors, risk assessment, lifestyle.

\section{INTRODUCTION}

Coronary atherosclerosis is a chronic process starting already early in life and progressing over years often silently. In 2006 the projections of global mortality and burden of disease from the World Health Organization expected an increase of cardiovascular disease (CVD), especially coronary heart disease (CHD), by around 30\% until 2030 [1]. Identification of the population at risk as early as possible and planning of specific interventions therefore is of great importance. CVD risk is the result of multiple interacting risk factors. Cardiovascular risk factor (CV-RF) assessment allows effective risk stratification to prevent major CVevents in all age groups. Screening and prevention of CVD

*Address correspondence to this author at the University Hospital Basel, Cardiology Department, Petersgraben 4, CH-4031 Basel, Switzerland;

Tel: +4161265 54 73; Fax: +416126545 98;

E-mail: michael.zellweger@usb.ch should be done as early in life as possible. Since the publication of the INTERHEART study [2] there is broad acceptance of cardiovascular risk scores. Risk scores are easily assessed and cheap. In Switzerland, the Working Group "Lipids and Atherosclerosis" (AGLA) from the Swiss Society of Cardiology has published adapted guidelines for Switzerland [3]. According to the "Harmonized guidelines on prevention of atherosclerotic cardiovascular diseases" from the International Atherosclerosis Society the AGLA Risk-Score (ARS) divides the risk scale into three risk categories with respect to the 10-years CVD morbidity: high risk (>20\% morbidity), intermediate risk (10-20\% morbidity) and low risk ( $<10 \%$ morbidity). As a promoter of preventive strategies in Switzerland the Swiss Heart Foundation raised several CV-risk prevention campaigns. CardioTest ${ }^{\circledR}$ is a pharmacy based risk assessment program recording the ARS of participating individuals allowing easy evaluation of individual risk factors. 
The aim of this study was threefold: to assess the CardioTest ${ }^{\circledR}$ campaign in daily practice as a quality control study, to evaluate the ability of CardioTest ${ }^{\circledR}$ regarding risk stratification, and to assess if the results of the test had impact on individual behaviour.

\section{METHODS}

\section{Study Population}

The CardioTest $^{\circledR}$ was started by the Swiss Heart Foundation and was carried out in 174 pharmacies all over Switzerland in the beginning. Meanwhile 477 pharmacies are certified CardioTest $^{\circledR}$ providers. The pharmacy personnel underwent training to carry out the CardioTest ${ }^{\circledR}$. The study evaluated consecutive individuals who were willing to provide written follow-up. Participants underwent measurements of blood pressure, body waist circumference, random blood samples for LDL-/HDL-Cholesterol, triglycerides and glucose measurements and were asked about their smoking habits and family history of CHD.

\section{Risk Factors}

Hypertension was defined as systolic blood pressure (BP) $>140 \mathrm{mmHg}$. Abdominal obesity was defined as waist circumference $>88 \mathrm{~cm}$ in women and $>102 \mathrm{~cm}$ in men. Cholesterol-levels (LDL-and HDL-cholesterol), triglycerides and glucose were measured and the AGLA-Risk score was calculated including smoking habits and family history of CHD. "Smoking" included only current smokers $(\geq 1$ cigarette per day) and family history of CHD was positive if one relative of first degree (male $\leq 55$ years of age, female $\leq$ 65 years of age) had a history of myocardial infarction or stroke.

The cardiovascular risk was calculated using the ARS according to the guidelines recommended by AGLA. Several calculators and charts to assess individual cardiovascular risk (CV-risk) have been developed in different countries and settings [4-6] but CV-risk and incidence of CHD vary considerably by ethnicity, country and region [7, 8]. While the Framingham Risk-Score [5] is the most common scoring algorithm in the United States, in Europe the PROCAMScore based on data from the Prospective Cardiovascular Münster study first published in 2002 [4] and revised in 2007 [9] is broadly available. For Switzerland, the Framingham risk function showed an overestimation of CV-events [10]. To calculate the CVD risk in regions different from Münster (Germany) the MONICA Regional Adjustment Factor (MRAF) is used. Because of the epidemiologic low CV-risk in Switzerland the AGLA recommends to use the PROCAMalgorithm for men and postmenopausal women with a diminishing MRAF of 0.7 correcting directly the post-test risk (accepting the falsification of the individual PROCAMtest specific likelihood ratio). For premenopausal women without diabetes with a very low CVD risk the guidelines recommend a combined diminishing MRAF of $0.25 * 0.7$.

As mentioned above the AGLA Risk-Score divides into three risk categories: high, intermediate and low. Low 10year cardiovascular risk $(<10 \%)$ was defined as 0 to 49 points by AGLA-calculator; intermediate risk (10\% - 20\%) was defined as 50 to 58 points and high risk (>20\%) as 59 points or more. Participants were immediately informed about their results and, if necessary, they were advised to contact their general practitioner immediately in order to perform additional work-up or to start treatment in individuals with ARS $>20 \%$ or metabolic syndrome and to modify their lifestyle in individuals with ARS $>10 \%$. Awareness of CardioTest $^{\circledR}$ and their motivation for participating were also assessed.

\section{Follow-up}

One year after initial testing individuals who had given written informed consent were followed up by a questionnaire that was distributed by mail. The questionnaire also focused on education, occupation and personal habits. The relation between ARS results and events during followup were assessed. Events were defined as cardiovascular events due to chest pain, myocardial infarction or stroke. Impact of testing was evaluated based on patient behavior after testing. Consultation and reason for consultation of their family doctor, smoking, and dietary habits were assessed.

\section{Statistical Analysis}

Continuous variables are described as the mean \pm standard deviation (SD) for the equally distributed, and as median for the non-equally distributed variables. Categorical and ordinal variables were compared using an x2-test. Continuous variables were compared using the T-or Mann Whitney-U test as appropriate. A p-value $<0.05$ was considered statistically significant. The analyses were performed with SPSS version 19.0 (SPSS, Inc., Chicago, IL, USA).

\section{RESULTS}

Initially, 1415 individuals agreed to participate in the follow-up examination one year after initial testing. Finally follow-up questionnaires were returned by 746 participants (53\%). The overall ARS test results (total points) of the baseline assessment was not different in the two groups, $36 \pm$ 11 and $35 \pm 13$ in participants with versus without follow-up, respectively, $\mathrm{p}=0.17$. However individuals not participating in the follow-up more likely were younger, smoker, and suffering from metabolic syndrome (data not shown). Most participants learned about CardioTest ${ }^{\circledR}$ through information material from the Swiss Heart Foundation (38\%) or directly by pharmacy personnel $(32 \%)$. Some noticed promotional advertisements published in journals or newspapers $(22 \%)$ and only a few were reached by other media (radio or television $1.6 \%$; internet $0.3 \%$ ), information by their family doctor $(0.5 \%)$, friends or relatives $(4.1 \%)$.

Table 1 summarizes the characteristics of the participants included in the study. A total of 746 individuals (male 60\%) with a mean age of $62.7 \pm 12.8$ years participated in the follow-up. They had normal body weight and quite a low risk profile, which resulted in an overall low ARS and thus low calculated cardiovascular risk (Fig. 1). Educational level of the tested population is summarized in Table 2 . The participants were well educated, $71 \%$ of the individuals had an occupationally specific education or a university degree. 
Table 1. Baseline characteristics follow-up population $(n=$ 748).

\begin{tabular}{|l|c|}
\hline Male sex (\%) & 59.9 \\
\hline Age (years) & $62.7 \pm 12.8$ \\
\hline Systolic blood pressure (mmHg) & $133 \pm 18$ \\
\hline Diastolic blood pressure (mmHg) & $80 \pm 10$ \\
\hline Smoker (\%) & 10.3 \\
\hline Positive family history of CHD (\%) & 17.6 \\
\hline LDL-cholesterol (mmol/L) & $3.0 \pm 1.3$ \\
\hline HDL-cholesterol (mmol/L) & $1.4 \pm 0.5$ \\
\hline Triclycerides (mmol/L) & $1.3 \pm 0.8$ \\
\hline Blood glucose (mmol/L) & $4.8 \pm 1.8$ \\
\hline Elevated waist circumference $(\%)$ & 28.8 \\
\hline Body Weight $(\mathrm{kg})$ & $69.6 \pm 13.5$ \\
\hline Body mass index $\left(\mathrm{kg} / \mathrm{m}^{2}\right)$ & $24.3 \pm 3.5$ \\
\hline
\end{tabular}

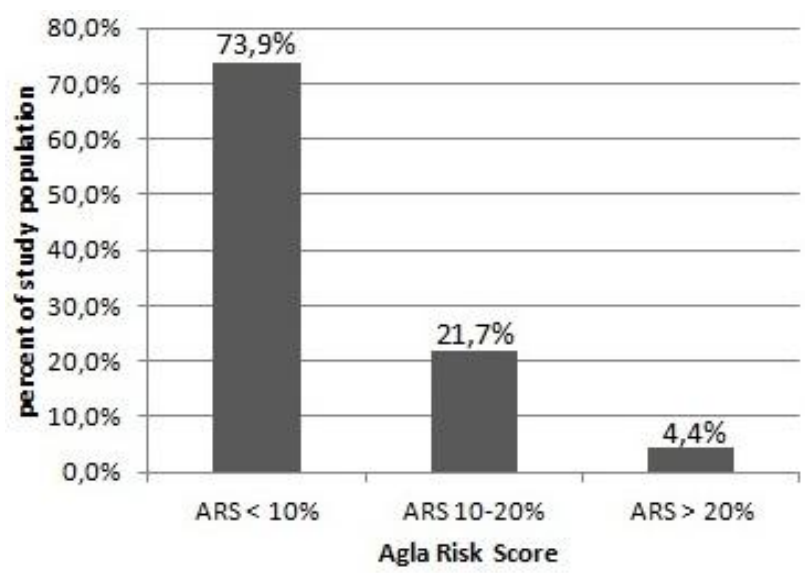

Fig. (1). Study population risk.

The majority of individuals participating in CardioTest ${ }^{\circledR}$ aimed at prevention $(56.5 \%)$. Some felt at risk for cardiovascular events $(13.0 \%)$ and others wanted to compare CardioTest ${ }^{\circledR}$ results with former tests they had done $(12.8 \%)$.
Some already had cardiovascular problems $(8.4 \%)$ or family members with a history of CVD $(5.3 \%)$ which motivated them to participate.

Table 2. Educational status according to ISCED $2011(\mathrm{n}=$ 734).

\begin{tabular}{|l|c|}
\hline & $\mathbf{( \% )}$ \\
\hline Level 0 - 2 (primary education / basic school) & 6.9 \\
\hline Level 3 - 4 (education providing skills relevant for employment) & 12.4 \\
\hline Level 5 (occupationally-specific education) & 60.6 \\
\hline Level 6 - 8 (university degree) & 10.8 \\
\hline other & 9.3 \\
\hline
\end{tabular}

\section{Risk Stratification and Impact of CardioTest ${ }^{\circledR}$}

$64(9 \%)$ individuals reported CV-events during followup. The event rates tended to increase as a function of ARS (Fig. 2). Significantly more participants with ARS $>20 \%$ consulted their family doctor because of the test results $(46.2 \%)$ or informed him during a routine visit $(63.0 \%)$ in comparison to the lower risk groups with ARS 10-20\% and ARS $<10 \%$, respectively ( $\mathrm{p}<0.01$ for all comparisons) (Fig. 3). The number of smokers at baseline was higher than at follow-up, $10.3 \%$ and $7.3 \%$, respectively $(\mathrm{p}<0.001)$. Thirtysix percent of the individuals mentioned to have changed their dietary habits to what they meant a "healthier diet".

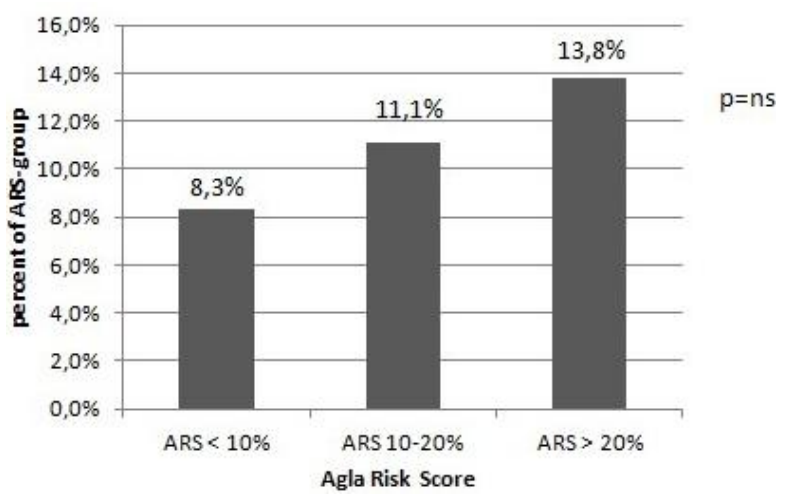

Fig. (2). Cardiovascular events.

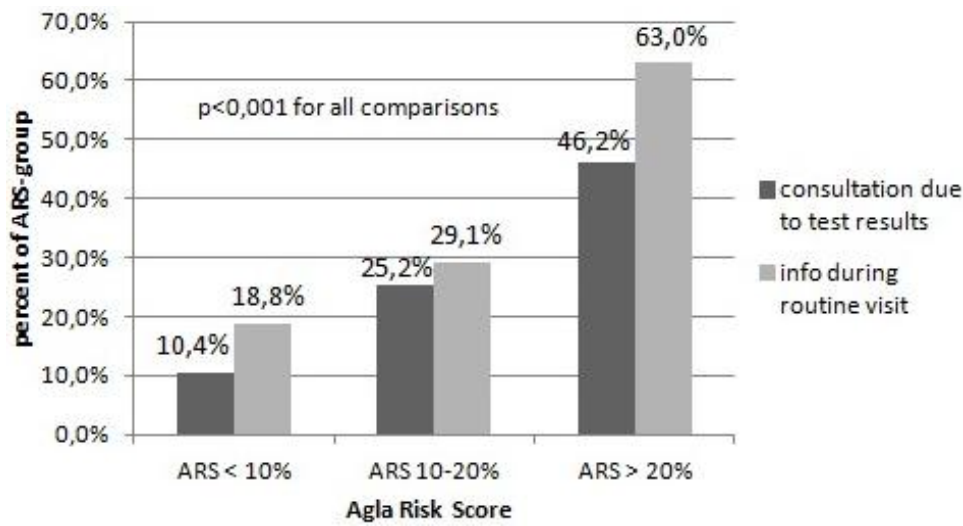

Fig. (3). Consultation of family doctor. 


\section{DISCUSSION}

CardioTest ${ }^{\circledR}$ risk assessment carried out in pharmacies most often addressed middle aged, well educated, healthconscious individuals who had a low CV-risk. However, test results were still effective in risk stratification and had impact on individual behavior.

Promotion seemed to play an important role to propagate CardioTest $^{\circledR}$ because a relevant part of participants mentioned having received either information from the Swiss Heart Foundation or having seen the CardioTest ${ }^{\circledR}$ opportunity when being at a pharmacy. Pharmacies per se probably are not the optimal spots to reach a higher risk population, thus rather often health-conscious individuals are visiting pharmacies or are costumers there. With a mean age of 62.7 years $( \pm 12.8)$ and a low risk profile the study population underrepresents the younger population at still higher cardiovascular risk, who might gain the highest benefit from screening programs.

Educational level of the study population is quite representative for the average educational level in Switzerland based on the report of the Swiss federal bureau of statistics 2011. In the majority of our study population occupationally specific education according to the International Standard Classification of Education 2011 [11] was the highest level of education similar to the general Swiss population $60.6 \%$ and $60.9 \%$, respectively. Rate of university degree or comparable education as highest educational level was lower in our study than in the general Swiss population $10.8 \%$ versus $27.6 \%$ in Swiss men and $21.7 \%$ in Swiss women. Throughout the study population there were less participants with compulsory school as highest level of education than the Swiss average (6.9\% vs. $11.5 \%$ in Swiss men and $17.4 \%$ in Swiss women).

In higher socioeconomic populations $\mathrm{CV}-\mathrm{RF}$ are reported to be lower, particularly for behaviors such as smoking, physical inactivity and body weight [12]. This leads to a higher mortality in lower socioeconomic populations [13]. Differences in risk factors corresponding to educational level have also been previously documented to be large for hypertension but less for dyslipidemia and diabetes [14]. The participants of CardioTest ${ }^{\circledR}$ follow-up are in a great part reflecting educational level of the Swiss population but those with lowest educational level seem to be underrepresented.

In other screening-programs participants were randomly chosen on the telephone [12] or were employees of a certain company [15] and comparisons with our study are therefore hampered.

There are only a few studies monitoring risk factors at a community level in Switzerland, mostly from the Frenchspeaking part of Switzerland [14, 16, 17]. In the „Lausanne Health Promotion Program" [15] the ARS was tested before implementation in the guidelines. While in other screening programs parts of the population of one city [18], employees of various companies in a Swiss region [15] or volunteering customers of different shopping malls in Switzerland participated [19]. In contrast, CardioTest ${ }^{\circledR}$ is available in all parts of Switzerland thus every region was represented. Prior studies revealed that individuals participating in studies for $\mathrm{CV}$-risk education had also a low risk and a low long-term mortality [20]. Nedeltchev et al. published data from the stroke prevention campaign "Meeting Point Heart and Brain" which took place in eight shopping malls in Switzerland in 2001 [19]. The majority of individuals who participated had one or two vascular risk factors. Overweight and arterial hypertension were by far most common and often were both present. Unpublished data from the prevention campaign "Treffpunkt Herz" collecting data in a bus in 32 Swiss Cities in 2004/2005 supported these results.

The CV-event rate in this study was low corresponding to a low overall CV-risk. Events increased as a function of ARS with highest event rates in those individuals with ARS $>20 \%$. CardioTest ${ }^{\circledR}$ provided risk stratification with respect to future CV-events. Systematic coronary risk evaluation (SCORE), Framingham Risk-Score and PROCAM-Score have the ability to predict future CV-events. With the Framingham Risk-Score the number of patients in the low risk group showing significant CHD is reported to be lower compared to PROCAM and SCORE [21] but Framingham Risk Score and PROCAM-Score are overestimating CHD in middle-aged men in some European regions [22]. There is conflicting data which of the scoring systems is superior and randomized trials comparing different risk stratification models are missing [23].

The pharmacy based CardioTest ${ }^{\circledR}$ based on AGLA data not only successfully risk stratified participants, it led as well to individual action depending on test results. As advised, more of those with high CV-risk consulted their family doctor due to their test result or at least informed him during a routine visit about CardioTest ${ }^{\circledR}$ results than in lower risk groups. This provided the opportunity to initiate medical interventions or treatment of CV-RF. It has been shown earlier that management and distribution of CV-RF differs geographically, even between different regions of Switzerland [24]. CardioTest ${ }^{\circledR}$ also seemed to have impact on individual behavior and life style modification. There were significantly less smokers at follow-up than at baseline $(7.3 \%$ vs. $10.3 \%, p=0.001)$ and one third of participants mentioned to have changed their dietary habits to in their opinion healthier food. A change in risk factors after screening programs with a reduction of hypertension, hypercholesterolemia and smoking was seen before, however obesity and sedentary lifestyle increased at follow-up [15].

\section{LIMITATIONS}

In this quality assessment study only 746 / 1415 (53\%) individuals sent their follow-up information back. However regarding overall risk as assessed by the AGLA score it was not different when comparing individuals who sent back the follow-up questionnaire and those who did not.

Since individuals who did send back the follow-up more likely were older, non-smokers, and not suffering from metabolic syndrome the results still are not generalizable. The subgroups, especially the high risk group was small in 
the current study. Therefore subgroup analysis is based on small patient populations.

\section{CONCLUSION}

The overall cardiovascular risk of individuals participating in a pharmacy based risk assessment program seems to be low. CardioTest ${ }^{\circledR}$ provided risk stratification with respect to future cardio-vascular events. CardioTest ${ }^{\circledR}$ seems to have impact on individual behavior and life style modification. Other settings and locations for screening might be considered to reach higher risk individuals at an earlier stage.

\section{CONFLICT OF INTEREST}

The authors confirms that this article content has no conflict of interest.

\section{ACKNOWLEDGEMENTS}

Declared none.

\section{REFERENCES}

[1] Mathers CD, Loncar D. Projections of global mortality and burden of disease from 2002 to 2030. PLoS Med 2006; 3: e442.

[2] Yusuf S, Hawken S, Ounpuu S, et al. Effect of potentially modifiable risk factors associated with myocardial infarction in 52 countries (the INTERHEART study): case-control study. Lancet 2004; 364: 937-52.

[3] Riesen W. DR, Noseda G., Bertel O., Buser P. et al. Empfehlungen zur Prävention der Artherosklerose. SAeZ 2005; 86: 1355-61.

[4] Assmann G, Cullen P, Schulte H. Simple scoring scheme for calculating the risk of acute coronary events based on the 10-year follow-up of the prospective cardiovascular munster (PROCAM) study. Circulation 2002; 105: 310-5.

[5] Wilson PW, D'Agostino RB, Levy D, Belanger AM, Silbershatz H, Kannel WB. Prediction of coronary heart disease using risk factor categories. Circulation 1998;97:1837-47.

[6] Conroy RM, Pyorala K, Fitzgerald AP, et al. Estimation of ten-year risk of fatal cardiovascular disease in Europe: the SCORE project. Eur Heart J. 2003;24:987-1003.

[7] D'Agostino RB Sr. Grundy S, Sullivan LM, Wilson P, Group CHDRP. Validation of the Framingham coronary heart disease prediction scores: results of a multiple ethnic groups investigation. JAMA 2001; 286: 180-7.

[8] Marrugat J, D'Agostino R, Sullivan L, et al. An adaptation of the Framingham coronary heart disease risk function to European Mediterranean areas. J Epidemiol Community Health 2003; 57: 634-8.
[9] Assmann G, Schulte H, Cullen P, Seedorf U. Assessing risk of myocardial infarction and stroke: new data from the prospective cardiovascular munster (PROCAM) study. Eur J Clin Invest 2007; 37: 925-32.

[10] Marques-Vidal P, Rodondi N, Bochud M, et al. Predictive accuracy of original and recalibrated Framingham risk score in the Swiss population. Int J Cardiol 2009; 133: 346-53.

[11] Unesco Institute for statistics accessed March, 26th, 2014: http://www.uis.unesco.org/Education/Documents/isced-2011en.pdf

[12] Stringhini S, Spencer B, Marques-Vidal P, et al. Age and gender differences in the social patterning of cardiovascular risk factors in Switzerland: the CoLaus study. PLoS One 2012; 7: e49443.

[13] Stringhini S, Sabia S, Shipley M, et al. Association of socioeconomic position with health behaviors and mortality. JAMA 2010; 303: 1159-66.

[14] Galobardes B, Costanza MC, Bernstein MS, Delhumeau C, Morabia A. Trends in risk factors for lifestyle-related diseases by socioeconomic position in Geneva, Switzerland, 1993-2000: health inequalities persist. Am J Public Health 2003; 93: 1302-9.

[15] Prior JO, van Melle G, Crisinel A, Burnand B, Cornuz J, Darioli R. Evaluation of a multicomponent worksite health promotion program for cardiovascular risk factors-correcting for the regression towards the mean effect. Prev Med 2005; 40: 259-67.

[16] Morabia A, Bernstein M, Heritier S, Ylli A. Community-based surveillance of cardiovascular risk factors in Geneva: methods, resulting distributions, and comparisons with other populations. Prev Med 1997; 26: 311-9.

[17] Wietlisbach V, Paccaud F, Rickenbach M, Gutzwiller F. Trends in cardiovascular risk factors (1984-1993) in a Swiss region: results of three population surveys. Prev Med 1997; 26: 523-33.

[18] Danon-Hersch N, Marques-Vidal P, Bovet P, et al. Prevalence, awareness, treatment and control of high blood pressure in a Swiss city general population: the CoLaus study. Eur J Cardiovasc Prev Rehabil 2009;16:66-72.

[19] Nedeltchev K, Arnold M, Baumgartner R, et al. Vascular risk factors in the Swiss population. J Neurol 2005; 252: 1210-6.

[20] Bopp M, Braun J, Faeh D, Gutzwiller F, Swiss National Cohort Study G. Establishing a follow-up of the Swiss MONICA participants (1984-1993): record linkage with census and mortality data. BMC Public Health. 2010;10:562.

[21] Versteylen MO, Joosen IA, Shaw LJ, Narula J, Hofstra L. Comparison of Framingham, PROCAM, SCORE, and Diamond Forrester to predict coronary atherosclerosis and cardiovascular events. J Nucl Cardiol 2011; 18: 904-11.

[22] Empana JP, Ducimetiere P, Arveiler D, et al. Are the Framingham and PROCAM coronary heart disease risk functions applicable to different European populations? The PRIME Study. Eur Heart J 2003; 24: 1903-11.

[23] Siontis GC, Tzoulaki I, Siontis KC, Ioannidis JP. Comparisons of established risk prediction models for cardiovascular disease: systematic review. BMJ 2012; 344: e3318.

[24] Marques-Vidal P, Paccaud F. Regional differences in self-reported screening, prevalence and management of cardiovascular risk factors in Switzerland. BMC Public Health 2012; 12: 246.

(C) Freund et al.; Licensee Bentham Open.

This is an open access article licensed under the terms of the Creative Commons Attribution Non-Commercial License (http://creativecommons.org/licenses/ by-nc/3.0/) which permits unrestricted, non-commercial use, distribution and reproduction in any medium, provided the work is properly cited. 